\title{
El principio de probidad administrativa en la jurisprudencia de la Contraloría General ${ }^{* *}$ The principle of administrative probity in the jurisprudence of the General Comptroller
}

Resumen

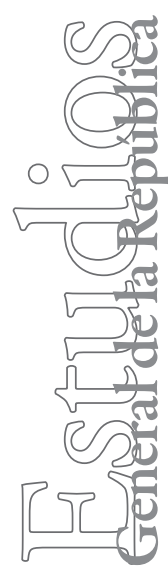

El presente trabajo realiza una revisión de la historia de la legislación estatutaria sobre el principio de probidad administrativa y analiza los dictámenes más recientes de la Contraloría General de la República que se han pronunciado sobre esta materia y sobre los conflictos de intereses y el deber de abstención de los funcionarios públicos, poniendo énfasis en las normas constitucionales que lo han complementado. Por último, revisa la jurisprudencia más reciente, en especial aquella relacionada con la responsabilidad del Presidente de la República y de los ministros de Estado.

Palabras clave:

Probidad administrativa, conflicto de interés, legislación estatutaria, deber de abstención.

* Master of Laws, Cornell University (NY). Profesor asistente del Departamento de Derecho Público de la Escuela de Derecho de la Universidad de Chile. Jefe de la División Jurídica de la Contraloría General de la República

**Artículo recibido el 24 de abril de 2013 y aceptado para su publicación el 4 de junio de 2013.

\section{Abstract}

This paper conducts a review of the history of statutory law on the principle of administrative probity and analyzes the most recent opinions of the Comptroller General of the Republic who have spoken on this subject and on conflict of interest and duty of abstention for public officials, emphasizing the constitutional norms that have complemented it. Finally, it checks the most recent jurisprudence, especially the one related to the responsibility of the President and the Ministers of State.

Key words:

Administrative probity, conflict of interests, statutory legislation, duty of abstention. 


\section{Introducción}

Tradicionalmente se argumenta que la corrupción produce efectos perniciosos para el desarrollo económico de la sociedad: afecta el crecimiento económico de las naciones especialmente de aquellas en desarrollo, distorsiona el dogma de la economía de mercado, produce ineficiencias en su funcionamiento, disminuye la inversión nacional y extranjera e incide negativamente en el nivel de ahorro privado. Así, la inversión extranjera directa reacciona negativamente ante la corrupción del sector público en los países en desarrollo y las economías más avanzadas castigan criminalmente los sobornos de sus empresas en las naciones más pobres.

A nivel político, se sostiene, que la corrupción daña la confianza en el sistema de gobierno democrático, en sus autoridades y en sus organismos, lo que se traduce en una pérdida de confianza ciudadana hacia las instituciones políticas y el Estado de Derecho. Introduce incertidumbres en la eficiencia del modelo económico, tolera la instauración de prácticas criminales que atentan contra la tranquilidad nacional y la convivencia internacional, tales como el tráfico ilícito de narcóticos, armas, materiales químicos y biológicos, incluso de inmigrantes, y el lavado de dinero.

En suma, se originan distorsiones en el modelo económico de libre mercado, aquel donde las decisiones se basan en la pretendida información perfecta, ocasionando la transferencia de recursos hacia sectores más ineficientes. Así existe una preocupación intensa y fecunda de estudios internacionales y de los organismos multilaterales que desarrollan programas de ayuda técnica y financiera a los países en desarrollo por enfrentar el dilema de los atentados a la ética pública. Estudios en este sentido abundan y esto ha servido para que las legislaciones nacionales y las convenciones internacionales hayan fomentado y aprobado leyes, regulaciones y políticas institucionales destinadas a identificar, prevenir y castigar la corrupción en los organismos públicos.

Esto es cierto y está bien que el ordenamiento jurídico, nacional e internacional, aborde este flagelo. Después de todo, de eso se preocupa el inciso cuarto del artículo $1^{\circ}$ de la Constitución Política de la República, cuando sostiene que el Estado está al servicio de la persona humana y su finalidad es promover el bien común, para lo cual debe contribuir a crear las condiciones sociales que permitan a todos y cada uno de los integrantes de la comunidad nacional su mayor realización espiritual y material posible, con pleno respeto de los derechos y garantías que la Carta Fundamental establece.

Los recursos que conforman el Tesoro Público son recursos que la comunidad, los contribuyentes, colocan a disposición del Estado para el cumplimiento de su fin básico: la promoción del bien común y el servicio de la persona humana. En particular, la Administración del Estado debe emplear estos dineros en la satisfacción de las necesidades colectivas de manera regular y continua. Pero los caudales públicos siguen siendo bienes de los contribuyentes y por ello las autoridades y funcionarios públicos son sólo meros administradores de fondos de terceros, por lo que deben invertirlos en mejorar la calidad de vida de la ciudadanía. Un sistema que permite que 
los dineros de los contribuyentes enriquezcan a quienes los administran no solo es un sistema repugnante, sino que es uno contrario a los principios más básicos del Estado de Derecho y las normas más elementales de justicia distributiva.

De este modo, se sostiene, que el principio de probidad administrativa significa simplemente que los recursos públicos no deben ir en el beneficio particular de quienes los gestionan. Esta es la noción tradicional de la probidad administrativa y con la que estamos acostumbrados a juzgar la conducta de nuestros gobernantes. Así no es extrańo que el estudio de la corrupción tenga el énfasis puesto en las consecuencias materiales o económicas de este fenómeno.

Sin embargo, a mi juicio esta es una condición necesaria pero en ningún caso suficiente para el adecuado cumplimiento de la función pública. En el siglo XXI podemos y debemos ser más exigentes con nuestras autoridades. Los recursos públicos deben ser gastados además respetando los principios de eficiencia, de eficacia, de economía y de oportunidad. Estos principios significan que se debe verificar el correcto empleo de los dineros de los contribuyentes; que se deben alcanzar los objetivos previstos; que se deben reducir los costos administrativos sin afectar la calidad y cantidad de los servicios que se proveen a los ciudadanos; y que todo esto debe hacerse en el momento preciso, cuando la necesidad pública está frente a nuestras narices. Cada peso gastado en un programa ineficiente, ineficaz, caro o inoportuno es un peso menos para la familia pobre que no puede costearse una salud digna, es un peso menos para el joven pobre pero talentoso que por una condición de origen no puede tener acceso a una educación que potencie sus talentos; es un peso menos para la viuda pobre que no tiene una jubilación que garantice su subsistencia; es un peso menos para los enfermos que necesitan un sistema de salud decente que atienda sus necesidades sanitarias más elementales. Es una cuestión de dignidad de la persona.

De allí la importancia de un diagnóstico preciso de las necesidades colectivas y del diseño conveniente de las políticas públicas, que no sea fruto del azar, sino que del trabajo continuo y perseverante. Después de todo, los milagros no existen, ni tampoco hay atajos para alcanzar la excelencia.

En suma, lo que estoy sosteniendo es que una concepción moderna del Estado de Derecho importa un estándar más estricto para evaluar el cumplimiento del principio de probidad administrativa: los dineros de los contribuyentes no solo no deben beneficiar ilícitamente a quienes los administran -conducta claramente dolosa-, si no que tampoco deben invertirse en programas absurdos aunque bien intencionados -conducta claramente culposa-.

Deben satisfacer las necesidades colectivas, pero respetando este nuevo estándar: de manera eficiente, eficaz, económica y oportuna, cierto, pero también que dignifique la persona humana. Esto es de lo que trata también el principio de servicialidad, crear las condiciones sociales que permitan a los integrantes de la comunidad su mayor realización espiritual posible. No se trata de que el Estado se preocupe de la felicidad de 
las personas, sino que fomente las condiciones para que los seres humanos busquen, de acuerdo con sus preferencias, su propia felicidad.

En este sentido, la probidad administrativa juega un rol esencial en el mantenimiento, preservación y fortalecimiento del Estado de Derecho. Una forma sencilla en la discusión sobre la probidad administrativa consiste en argumentar que las potestades discrecionales de los órganos públicos deben ser limitadas al máximo. Sin embargo, un sistema de potestades tasadas no es compatible con la dificultad que importa la gestión de los negocios públicos en el siglo XXI. La Administración actual del Estado es un sistema complejo: las necesidades públicas que asume el Estado son cada vez de mayor complejidad, la ciudadanía es cada vez más consciente de sus derechos frente a los poderes públicos (las demandas de transparencia y participación social son una muestra de este fenómeno), los recursos públicos son cada vez mayores y la sofisticación de su ejecución es por su naturaleza enredada.

Ello lleva a concluir que tasar las potestades de los órganos de la Administración del Estado y de sus autoridades no solo no es jurídicamente viable, sino que ineficiente y contrario a las bases propias del Estado de Derecho, que reconoce que corresponde a la Administración activa la administración de los intereses públicos. La solución más bien apunta a la creación de estándares de conducta que rescaten la discrecionalidad de los funcionarios, el criterio, para que dentro de los límites que fija el ordenamiento jurídico, puedan actuar.

\section{El desarrollo legislativo sobre la probidad administrativa y los primeros pronunciamientos}

En los primeros pronunciamientos, la Contraloría General asoció el principio de probidad con el cumplimiento de deberes morales, que era el nombre del Párrafo 5 del Título III, denominado "Obligaciones y Prohibiciones de los Funcionarios Públicos" del antiguo Estatuto Administrativo'. En particular, el artículo 154 sostenía que "El empleado debe comportarse con dignidad en el desempeño de su cargo y en su vida social, como, asimismo, guardar respeto y lealtad a sus jefes y compañeros del Servicio y, de un modo general, al personal de la Administración, siempre que con ello no se incurra en alguna omisión sancionada por este Estatuto, el Código Penal u otras leyes especiales.".

Resulta curioso que este texto legal no contuviera alguna mención al principio de probidad, lo que no impidió que la jurisprudencia hiciera mención al mismo, sosteniendo, por ejemplo, que los empleados públicos pueden imponerse de las resoluciones de sus superiores en sus solicitudes y otros documentos cuando no revisten el carácter de reservados ${ }^{2}$, que un funcionario puede ser propietario de un restaurante siempre que 
ejerza este negocio sin perjuicio de sus obligaciones funcionarias y sin afectar la dignidad de su comportamiento en la vida social ${ }^{3}$, que los servidores pueden publicar folletos sobre divulgación sindical, pero no puede financiarlos con avisos económicos ${ }^{4}$, que las autoridades inferiores deben referirse con respeto a sus jefaturas ${ }^{5}$, que el concepto de "funcionario de superior jerarquía" que emplea el Estatuto entonces vigente está usado en un sentido amplio, comprensivo no solo de los superiores jerárquicos dentro del mismo servicio, sino que en el ámbito de la Administración del Estado, quedando, en consecuencia, comprendidos en dicho concepto los ministros de Estado, aun cuando no puedan ser considerados empleados o funcionarios y no se les aplique el decreto con fuerza de ley $\mathrm{N}^{\circ} 338^{6}$, que el legislador reconoce en términos amplios los derechos de los funcionarios a realizar actividades privadas, pero condiciona su ejercicio a que la profesión, industria o comercio que desarrolla el empleado sea conciliable con la posición que ocupa en la Administración del Estado y que esa actividad no importe un menoscabo del cumplimiento de las obligaciones que afectan a los servidores públicos ${ }^{7}$, o que el ejercicio de una función pública impone al empleado determinados deberes que no solo abarcan sus actuaciones en el desempeńo mismo del cargo dentro del servicio y durante la jornada de trabajo, sino que también se extienden a su comportamiento fuera de aquel ${ }^{8}$.

A su vez manifestó que el artículo 162 del decreto con fuerza de ley $\mathrm{N}^{\circ} 338$, de 1960 no solo contempla una prohibición que obliga al empleado público a abstenerse de intervenir en el ejercicio de su empleo en asuntos que le intereses, sino que obedece a un principio de probidad administrativa que debe guiar todas las actividades que realicen los servidores de la administración pública y que informa las normas estatutarias contenidas en el antedicho texto normativo. ${ }^{9}$

También sostuvo que no es procedente que profesionales y técnicos que realizan funciones inspectivas relacionadas con la higiene y seguridad industrial, realicen labores de asesoría en este aspecto en el sector privado, aunque lo hagan fuera del territorio jurisdiccional en que ejercen labores fiscalizadoras en atención a que si bien es efectivo que la actividad del órgano público respectivo se efectúa separadamente en diversas zonas de salud que contempla la estructura orgánica del servicio, lo cierto es que esa entidad tiene competencia general para la supervigilancia de la higiene, seguridad e instalaciones médicas de todos los sitios de trabajo, por lo cual, en estos profesionales se daría una coincidencia entre la labor que ejecuta el profesional como servidor del Estado y su actividad como particular. Por tal motivo, las prerrogativas o esfera de

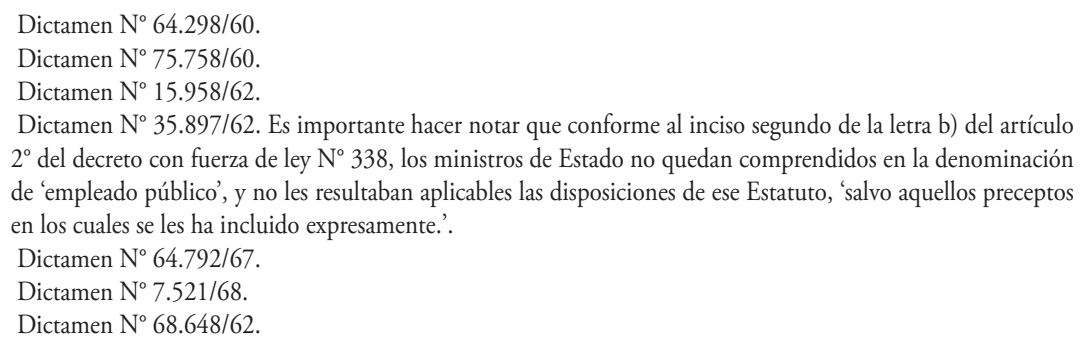


influencia del funcionario se proyectarán en su actividad particular, debido a que si todos los profesionales del servicio desempeñan aquella especie de asesoría, existe el riesgo de que esos empleados se fiscalicen recíprocamente vulnerando el principio de la probidad administrativa ${ }^{10}$.

Con la dictación de la ley Nº 18.575, Orgánica Constitucional de Bases Generales de la Administración del Estado (en lo sucesivo, Ley de Bases) ${ }^{11}$, se incorpora a nuestro ordenamiento jurídico la expresión probidad administrativa. Así su artículo $7^{\circ}$ prevenía que "Los funcionarios de la Administración del Estado estarán afectos a un régimen jerarquizado y disciplinado. Deberán cumplir fiel y esmeradamente sus obligaciones para con el servicio, obedecer las órdenes que les imparta el superior jerárquico y observar estrictamente el principio de probidad administrativa, que implica una conducta funcionaria moralmente intachable y una entrega honesta y leal al desempeño de su cargo, con preeminencia del interés público sobre el privado.”.

Resulta curioso pero en el período en que rigieron simultáneamente esta ley y el antiguo Estatuto Administrativo solo hubo dos dictámenes relevantes. El año 1988 la Contraloría General sustentó la tesis de que la venta de bienes muebles pertenecientes a la Comisión Chilena de Energía Nuclear que ella realiza de modo directo y habitual a sus empleados, no serían objetables siempre que no correspondan a un proceso habitual y masivo fundamentado en leyes especiales, que a los empleados en razón de sus funciones no les competa intervenir ni directa ni indirectamente en la decisión de vender o en cualquier acto relativo a la enajenación, ni se dé, tampoco, entre el interesado y los funcionarios que sí intervienen en el proceso de venta, el grado de parentesco señalado en el artículo 162 del antiguo decreto con fuerza de ley $\mathrm{N}^{\circ} 338^{12}$, pues los principios de probidad administrativa contemplados sus artículos $98^{13}, 162$ y $163^{14}$ son inherentes al ejercicio de la función pública y, en tal virtud, deben aplicarse a todos los empleados de la Administración Estatal, central o descentralizada. En tal sentido, manifestó que esta conclusión era procedente aun cuando los estatutos legales que los rijan no contemplen reglas como las consagradas en dichos preceptos, lo que se ve confirmado por el artículo $7^{\circ}$ de la aludida Ley de Bases. Así concluyó que los

Dictamen $\mathrm{N}^{\circ} 7.521 / 68$.

Publicada en el Diario Oficial el 5 de diciembre de 1986.

Conforme al cual "El empleado no podrá intervenir, en razón de sus funciones, en asuntos en que tenga interés él, su cónyuge, sus parientes consanguíneos del primero al cuarto grado, inclusive, o por afinidad comprendidos entre el primero y el segundo grado, o las personas ligadas con él por adopción. La infracción a esta prohibición será sancionada con alguna medida disciplinaria que implique la expiración de las funciones del infractor.”.

13 Tal precepto prevenía que "Todo empleado tiene derecho a ejercer libremente cualquiera profesión, industria, comercio u oficio conciliable, con su posición, en la Administración, siempre que con ello no se perturbe el fiel y oportuno cumplimiento de sus deberes funcionarios, sin perjuicio de las prohibiciones o limitaciones establecidas en las leyes o reglamentos orgánicos de cada Servicio.".

14 Según este artículo "El empleado no podrá actuar directa o indirectamente contra los intereses del Estado o de las Instituciones que de él formen parte, salvo de que se trate de un derecho que le atańe directamente a él, a su cónyuge o a sus parientes hasta el segundo grado de consanguinidad, inclusive.". Su inciso segundo ańadía que "Tampoco podrá intervenir ante los Tribunales de Justicia como parte, testigo o perito, respecto de hechos de que hubiere tomado conocimiento en el ejercicio de sus funciones, ni declarar en juicio en que tenga interés el Estado, sin previa comunicación su Jefe Superior.”. 
empleados no pueden adquirir bienes de la entidad a que pertenecen, cuando se trata de venta que tienen un carácter habitual y de orden masivo, autorizadas por leyes especiales, ya que si ellas se permitieran efectuar preferencialmente entre una determinada repartición y sus propios trabajadores, los intereses del Fisco podrían verse afectados, pues es manifiesto que esos personales, al representar y proteger sus propios intereses, podrían ir en desmedro de los de aquel, situación que resulta inadmisible ${ }^{15}$.

El segundo dictamen dijo relación con la compatibilidad entre la libertad de trabajo y el desempeño de la función pública. Este pronunciamiento confirmó una jurisprudencia antigua ${ }^{16}$, conforme a la cual los arquitectos, ingenieros civiles y constructores civiles que laboran en unidades de desarrollo urbano e infraestructura de las Secretarias Ministeriales de Vivienda y Urbanismo no pueden ejercer libremente su profesión. Manifestó que ese criterio no vulnera las garantías constitucionales sobre libertad de trabajo y de igualdad ante la ley, consagradas en los números 16 y 2 , respectivamente, del artículo 19 de la Constitución Política de la República, pues el artículo 98 del decreto con fuerza de ley $\mathrm{N}^{\circ} 338$, es un precepto de carácter estatutario que, consagrando un amplio principio de probidad administrativa, limita el uso de la libertad de ejercicio profesional, industrial o comercial por parte de los empleados públicos e impone a estos el deber de evitar que sus prerrogativas o esferas de influencia se proyecten en sus actividades particulares, lo que puede darse fácilmente cuando estas inciden o se relacionan con el campo de las labores de la repartición en la que sirven.

A juicio de la Contraloría este precepto se confirma con el artículo $7^{\circ}$ de la ley $\mathrm{N}^{\circ}$ 18.575, que obliga a los funcionarios públicos a observar estrictamente el principio de probidad administrativa. Finalizó sosteniendo que dicho pronunciamiento no significa, no obstante, una limitación absoluta para el ejercicio liberal de la profesión, porque de su contexto se infiere que tal limitante se relaciona solo con el territorio jurisdiccional de la unidad en que ellos cumplen sus funciones ${ }^{17}$.

Con la dictación de la ley $\mathrm{N}^{\circ} 18.834$, que aprobó el nuevo Estatuto Administrativo ${ }^{18}$, se incorporó como una obligación funcionaria "Observar estrictamente el principio de probidad administrativa, que implica una conducta funcionaria moralmente intachable y una entrega honesta y leal al desempeño de su cargo, con preeminencia del interés público sobre el privado" ${ }^{19}$. Es interesante hacer notar que en la historia de esta ley quedó de manifiesto que los "deberes morales" a que hacía alusión el decreto con fuerza de ley $\mathrm{N}^{\circ} 338$ no son sino expresión del principio de probidad administrativa que regula el nuevo texto legal.

Una nueva etapa del desarrollo legislativo sobre la ética pública comenzó con la aprobación de la ley $\mathrm{N}^{\circ} 19.653^{20}$, que además de efectuar modificaciones singulares

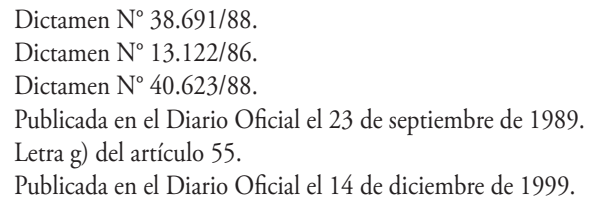


al Título I de la ley $\mathrm{N}^{\circ} 18.575^{21}$, incorporó un Título III nuevo, denominado precisamente "De la Probidad Administrativa". Este Título III, al igual que el Título I, se aplica a todos los órganos de la Administración del Estado, la cual está integrada de la forma definida por el artículo $1^{\circ}$, esto es, "por los Ministerios, las Intendencias, las Gobernaciones y los órganos y servicios públicos creados para el cumplimiento de la función administrativa, incluidos la Contraloría General de la República, el Banco Central, las Fuerzas Armadas y las Fuerzas de Orden y Seguridad pública, los Gobiernos Regionales, las Municipalidades y las empresas públicas creadas por ley.”.

Así, la Ley Orgánica Constitucional de Bases Generales de la Administración del Estado estableció un conjunto de normas tendientes a cautelar este principio: el establecimiento de los principios de publicidad y transparencia -elevados después a rango constitucional-, la instauración de reglas generales que lo definen y tipifican conductas que lo transgreden, la elaboración expresa de inhabilidades e incompatibilidades administrativas que afectan a servidores públicos, la obligación de presentar una declaración pública ${ }^{22}$ de intereses ${ }^{23} \mathrm{y}$ un régimen estricto de responsabilidades y sanciones por las infracciones al nuevo Título III.

Finalmente, el año 2005 se dicta la ley $\mathrm{N}^{\circ} 20.050$, que reforma sustancialmente la Constitución Política de la República ${ }^{24}$, incorporando un artículo $8^{\circ}$, que a la fecha se encontraba derogado, cuya nueva redacción sostiene que el ejercicio de las funciones públicas obliga a sus titulares a dar estricto cumplimiento al principio de probidad en todas sus actuaciones.

21 Publicada en el Diario Oficial el 14 de diciembre de 1999.

22 El Tribunal Constitucional analizó la constitucionalidad del precepto que establecía esta obligación y que entrega a un reglamento establecer los requisitos de las declaraciones de intereses y las demás normas necesarias para dar cumplimiento a las disposiciones del párrafo que lo regulan. Así, declaró, en el №2 de la sentencia rol ํo 299, que "el artículo 62, del nuevo Título III de la Ley No 18.575, Orgánica Constitucional de Bases Generales de la Administración del Estado, agregado por el Artículo $2^{\circ}$, del proyecto de ley en estudio, es constitucional en el entendido de lo señalado en el considerando $9^{\circ}$, de esta sentencia.". El considerando $9^{\circ}$ seńaló que el Tribunal "estima que el [artículo 62] es constitucional en el entendido de que el reglamento a que alude sólo ha de contemplar los requisitos de forma de la declaración de intereses o de su actualización, sin ampliar el contenido de la misma, el que se encuentra determinado por los artículos 60 y 61 ".

23 A la cual la ley $\mathrm{N}^{\circ} 20.088$, publicada en el Diario Oficial el 5 de enero de 2006, agregaría el deber de presentar una declaración de patrimonio, obligación que al discutirse la ley $\mathrm{N}^{\circ} 19.653$, fue descartada. Dentro de las curiosidades con que de tanto en tanto nos sorprende nuestra jurisdicción constitucional, el Tribunal Constitucional sostuvo que "la hermenéutica razonable, finalista y el principio de presunción de constitucionalidad, sostenidos reiteradamente por esta Magistratura, llevan a aseverar que la alusión al conocimiento y consulta pública en forma irrestricta de dichas declaraciones a que se refieren los artículos citados en el considerando precedente, debe ser entendida en el sentido que, el acceso por terceros a esa información, ha de serlo para las finalidades legítimas que la nueva normativa persigue, circunstancia esencial que exige, de todos los órganos del Estado involucrados por tales disposiciones, interpretarlas y aplicarlas con el objetivo señalado" (Tribunal Constitucional, rol 460, considerando $31^{\circ}$, énfasis en el original). Pero además es particularmente llamativo que el Tribunal haya precisado en un fallo los términos en que debe entenderse una ley y que además haya instruido a los Órganos del Estado (no solo a los órganos de la Administración del Estado como la Contraloría General de la República, sino que también al Congreso Nacional y al Poder Judicial) acerca de cómo deben interpretar una norma legal.

24 Aunque también a otros textos legales, como a la ley No 19.175, Orgánica Constitucional de Gobierno y Administración Regional; a la ley No 18.695, Orgánica Constitucional de Municipalidades; a la ley No 18.834 , sobre Estatuto Administrativo; a la ley No 18.883, sobre Estatuto Administrativo de los Funcionarios Municipales; a la ley No 18.918, Orgánica Constitucional del Congreso nacional; al Código Orgánico de Tribunales; a la ley №15.231; a la ley No18.046, y a la ley No18.840, Orgánica Constitucional del Banco Central de Chile. 
El inciso segundo añade que "Son públicos los actos y resoluciones de los órganos del Estado, así como sus fundamentos y los procedimientos que utilicen. Sin embargo, sólo una ley de quórum calificado podrá establecer la reserva o secreto de aquéllos o de éstos, cuando la publicidad afectare el debido cumplimiento de las funciones de dichos órganos, los derechos de las personas, la seguridad de la Nación o el interés nacional.”.

De este modo, el principio de probidad pasó de tener un mero significado jurisprudencial -que en definitiva se limitaba a identificar conductas que transgredían o podían transgredirlo-, basado en la idea de deberes morales que establecía el antiguo Estatuto Administrativo, a un reconocimiento legal, primero en la ley $\mathrm{N}^{\circ} 18.575$, luego en la ley $\mathrm{N}^{\circ} 18.834$ y por último como máxima aplicable a todos los Órganos de la Administración del Estado y, consecuentemente a todos sus funcionarios, cualquiera que fuera la posición que en ella ocuparan, para por último, ser instaurado como precepto constitucional exigible, y fiscalizable, a todos quienes desempeñen una función pública, con independencia de cuál sea esa labor, es decir, en una concepción amplia además de vinculante.

\section{El marco normativo básico}

En la actualidad el marco jurídico básico, no excluyente por cierto, que regula la probidad administrativa es el siguiente: Por una parte, el artículo $8^{\circ}$ de la Constitución Política de la República que previene que "El ejercicio de las funciones públicas obliga a sus titulares a dar estricto cumplimiento al principio de probidad en todas sus actuaciones".

A continuación, el inciso segundo del artículo $3^{\circ}$ de la Ley de Bases señala los principios que debe observar la Administración del Estado, entre los cuales se encuentra el de probidad administrativa, mencionado en el inciso primero de su artículo 13, conforme al cual "Los funcionarios de la Administración del Estado deberán observar el principio de probidad administrativa y, en particular, las normas generales y especiales que lo regulan.”. Esta referencia a las 'normas especiales' se relaciona con el hecho que el inciso segundo del artículo 43 previene que "Cuando las características de su ejercicio lo requieran, podrán existir estatutos de carácter especial para determinadas profesiones o actividades". Estos 'estatutos especiales' están mayoritariamente mencionados en el artículo 162 del Estatuto Administrativo, el cual finaliza señalando que los funcionarios afectos a esos textos particulares "se sujetarán a las normas de este Estatuto Administrativo en los aspectos o materias no regulados por sus estatutos especiales." ${ }^{25}$.

25 Los funcionarios que conforme a este precepto ejercen 'profesiones y actividades' especiales son:

a) Académicos de las instituciones de Educación Superior;

b) Personal afecto a la ley No 15.076 ;

c) Personal del Servicio Exterior del Ministerio de Relaciones Exteriores. Asimismo el personal de la planta de Secretaría y Administración General del Ministerio de Relaciones Exteriores y de los Servicios Públicos sometidos a la dependencia del Presidente de la República, a través de este Ministerio, cuando cumplan funciones en el extranjero; 
Además, el inciso primero del artículo 52 de la ley $\mathrm{N}^{\circ} 18.575$ previene que "Las autoridades de la Administración del Estado, cualquiera que sea la denominación con que las designen la Constitución y las leyes, y los funcionarios de la Administración Pública, sean de planta o a contrata, deberán dar estricto cumplimiento al principio de la probidad administrativa", y ańade su inciso segundo que este principio "consiste en observar una conducta funcionaria intachable y un desempeńo honesto y leal de la función o cargo, con preeminencia del interés general sobre el particular.", por lo que su inobservancia, según su inciso tercero, "acarreará las responsabilidades y sanciones que determinen la Constitución, las leyes y el párrafo $4^{\circ}$ de este Título, en su caso.”.

Entonces, este principio pivota sobre la base del 'interés general', el que, conforme al artículo 53, exige el empleo de medios idóneos de diagnóstico, decisión y control, para concretar, dentro del orden jurídico, una gestión eficiente y eficaz. Es interesante hacer notar que el legislador orgánico se preocupó de definir cómo se expresa este interés general:

- $\quad$ el recto y correcto ejercicio del poder público por parte de las autoridades administrativas;

- $\quad$ en lo razonable e imparcial de sus decisiones;

- $\quad$ en la rectitud de ejecución de las normas, planes, programas y acciones;

- $\quad$ en la integridad ética y profesional de la administración de los recursos públicos que se gestionan;

- $\quad$ en la expedición en el cumplimiento de sus funciones legales, y

- $\quad$ en el acceso ciudadano a la información administrativa, en conformidad a la ley.

d) Personal de la planta de oficiales y vigilantes penitenciarios de Gendarmería de Chile;

e) Personal que cumpla funciones fiscalizadoras en la Fiscalía nacional Económica, el Servicio Nacional de Aduanas, el Servicio de Impuestos Internos, la Superintendencia de Bancos e Instituciones Financieras, la Superintendencia de Valores y Seguros, la Superintendencia de Seguridad Social, la Superintendencia de Administradoras de Fondos de Pensiones y la Dirección del Trabajo, y

f) El personal que desempeńa actividades directamente vinculadas a la actividad televisiva en la Corporación de Televisión de la Universidad de Chile.

Sin embargo, esta enumeración es meramente enunciativa, pues para el personal de la Administración del Estado que está sujeto al Código del Trabajo, éste es su 'estatuto especial'. Así como algunos autores hablan de la huida del derecho administrativo, este fenómeno de la sujeción de quienes sirven cargos públicos al amparo del derecho privado, esto es, el Código del Trabajo, este fenómeno ha sido llamado la laborización del empleo público.

Respecto de esta figura la Contraloría General de la República ha sostenido que "Cuando por mandato legal se afecta a los funcionarios de entidades de la Administración del Estado a la legislación laboral común, esta última adquiere, tanto para ellos como para la institución, el carácter de estatuto jurídico de derecho público, en razón de la naturaleza del organismo y la especialidad del vínculo que existe entre ambos, por lo cual dicha legislación aplica dentro del marco de principios y normas peculiares -en materia de investidura, de competencia y de responsabilidad, entre otras-, reconocidos por la Constitución Política, y que no tienen aplicación tratándose de relaciones laborales del sector privado" (dictamen $\mathrm{N}^{\circ} 25.332 / 08$, y en el mismo sentido se pronuncian los oficios $\mathrm{N}^{\circ}$ s. 65.176/00, 62.498/08, 47.184/07, 44.405/0731.116/01 y 19.383/01). 
Finalmente, el artículo 62 de la misma ley $\mathrm{N}^{\circ} 18.575$ tipifica un conjunto de actuaciones que afectan esta obligación. Señala que "Contravienen especialmente el principio de la probidad administrativa, las siguientes conductas:

1. Usar en beneficio propio o de terceros la información reservada o privilegiada a que se tuviere acceso en razón de la función pública que se desempeña;

2. Hacer valer indebidamente la posición funcionaria para influir sobre una persona con el objeto de conseguir un beneficio directo o indirecto para sí o para un tercero;

3. Emplear, bajo cualquier forma, dinero o bienes de la institución, en provecho propio o de terceros;

4. Ejecutar actividades, ocupar tiempo de la jornada de trabajo o utilizar personal o recursos del organismo en beneficio propio o para fines ajenos a los institucionales;

5. Solicitar, hacerse prometer o aceptar, en razón del cargo o función, para sí o para terceros, donativos, ventajas o privilegios de cualquier naturaleza.

Exceptúanse de esta prohibición los donativos oficiales y protocolares, y aquellos que autoriza la costumbre como manifestaciones de cortesía y buena educación.

El millaje u otro beneficio similar que otorguen las líneas aéreas por vuelos nacionales o internacionales a los que viajen como autoridades o funcionarios, y que sean financiados con recursos públicos, no podrán ser utilizados en actividades o viajes particulares;

6. Intervenir, en razón de las funciones, en asuntos en que se tenga interés personal o en que lo tengan el cónyuge, hijos, adoptados o parientes hasta el tercer grado de consanguinidad y segundo de afinidad inclusive.

Asimismo, participar en decisiones en que exista cualquier circunstancia que le reste imparcialidad.

Las autoridades y funcionarios deberán abstenerse de participar en estos asuntos, debiendo poner en conocimiento de su superior jerárquico la implicancia que les afecta;

7. Omitir o eludir la propuesta pública en los casos que la ley la disponga;

8. Contravenir los deberes de eficiencia, eficacia y legalidad que rigen el desempeńo de los cargos públicos, con grave entorpecimiento del servicio o del ejercicio de los derechos ciudadanos ante la Administración, y

9. Efectuar denuncias de irregularidades o de faltas al principio de probidad de las que haya afirmado tener conocimiento, sin fundamento y respecto de las cuales se constatare su falsedad o el ánimo deliberado de perjudicar al denunciado.”.

No es el propósito de este trabajo establecer las vinculaciones de otros preceptos legales con este artículo 62. Son evidentes las relaciones que existen con el deber de abstención que impone la ley $\mathrm{N}^{\circ} 19.880$ o con la obligación de realizar licitaciones 
públicas, en cuanto son el mecanismo natural de contratación, según diversos textos legales, en especial, conforme a la ley $\mathrm{N}^{\circ}$ 19.886. Quiero destacar solo dos ideas. La primera es la amplitud que la jurisprudencia ha dado a este deber. Así ha sostenido que este artículo dispone que contravienen especialmente el principio de probidad las conductas que a continuación enumera, lo que demuestra que el legislador no ha limitado a un número determinado las actuaciones funcionarias que vulneran dicha directriz de desempeño, sino que, por el contrario, se ha preocupado de dejar claramente establecido cuáles conductas no pueden dejar de ser consideradas como una transgresión del referido principio ${ }^{26}$, y así, por ejemplo, ha extendido su aplicación a los concejales, aun cuando no poseen la calidad de funcionarios públicos ${ }^{27}$ y a las personas contratadas a honorarios ${ }^{28}$.

La segunda es que el artículo 125 del Estatuto Administrativo indica que "La destitución es la decisión de la autoridad facultada para hacer el nombramiento de poner término a los servicios de un funcionario.". A continuación, y esto es lo que me interesa destacar, añade que esta medida disciplinaria procede "sólo cuando los hechos constitutivos de la infracción vulneren gravemente el principio de probidad administrativa" 29 .

La pregunta entonces es si la expresión contravienen especialmente el principio de la probidad administrativa debe entenderse vinculada con la consecuencia que implica vulnerar gravemente el principio de probidad administrativa. Dicho de otro modo, si un funcionario incurre en alguna de las conductas definidas por el artículo 62 de la ley $\mathrm{N}^{\circ} 18.575$ debe necesariamente ser destituido conforme al artículo 125 del Estatuto Administrativo.

La Contraloría analizó el caso de una funcionaria respecto de la cual se instruyó un proceso disciplinario del cual resultó evidente que ella realizó diversas contrataciones sin sujetarse a los procedimientos de contratación que exigen la ley $\mathrm{N}^{\circ} 19.886$, de Bases sobre Contratos Administrativos de Suministro y Prestación de Servicios, y su reglamento, aprobado por el decreto supremo $\mathrm{N}^{\circ} 250$, de 2004, del Ministerio de Hacienda, normativa que resultaba aplicable a los hechos por los cuales se dispuso el procedimiento sumarial. El servicio se limitó a aplicar a la infractora una "multa consistente en la privación de un $20 \%$ de su remuneración mensual”.

Pues bien, la Contraloría General sostuvo que la funcionaria incurrió en conductas que "contravienen especialmente el principio de la probidad administrativa, previstas en los artículos $62, \mathrm{~N}^{\circ} 7$, y 8 de la ley $\mathrm{N}^{\circ} 18.575, \ldots$, en relación con lo dispuesto en

26 Dictámenes Nos. 49.659/11, 42.592/11, 34.834/10, 7.727/10, 61.379/08, 49.580/08, 26.949/07, 5.670/07, 58.851/04, 40.152/04, 16.115/04, 39.410/03 y 30.733/00).

Dictámenes $\mathrm{N}^{\circ}$ s. $15.401 / 11$ y $18.721 / 02$.

Dictámenes $\mathrm{N}^{\circ}$ s. 6.591/00, 39.497/00 y 140/04.

Las otras causales son a) Ausentarse de la institución por más de tres días consecutivos, sin causa justificada; b) Infringir las disposiciones de las letras i), j) y k) del artículo 84 de ese Estatuto; c) Condena por crimen o simple delito; d) Efectuar denuncias de irregularidades o de faltas al principio de probidad de las que haya afirmado tener conocimiento, sin fundamento y respecto de las cuales se constatare su falsedad o el ánimo deliberado de perjudicar al denunciado, y e) En los demás casos contemplados en este Estatuto o leyes especiales.". 
el artículo 52 de la misma ley.”. En virtud de ello concluyó que "teniendo en cuenta que ha quedado fehacientemente acreditada la efectiva responsabilidad de la inculpada en las actuaciones anómalas que le fueran imputadas, esta Entidad Fiscalizadora debe concluir que la medida disciplinaria correctiva dispuesta en la especie, no condice con la entidad de aquellas, las que configuran una grave falta al principio de probidad administrativa, que amerita ser sancionada con la destitución de su cargo, acorde con lo establecido en el inciso segundo del artículo 125 de la ley $\mathrm{N}^{\circ} 18.834$, sobre Estatuto Administrativo.".

Finalizó agregando que "cuando la ley asigna una medida disciplinaria específica para determinada infracción, la autoridad administrativa se encuentra en el imperativo de disponerla, no pudiendo ejercer las atribuciones privativas que le permiten determinar aquélla que, a su juicio, merecería el comportamiento anómalo observado por la afectada, ni menos ponderar circunstancias que eventualmente podrían aminorar su responsabilidad funcionaria. En este mismo orden de ideas, conviene precisar que si bien el inciso final del artículo 121 de la ley $\mathrm{N}^{\circ}$ 18.834, sobre Estatuto Administrativo, establece que las medidas disciplinarias se aplicarán tomando en cuenta la gravedad de la falta y las circunstancias atenuantes o agravantes que arroje el mérito de los antecedentes, tal disposición sólo rige para las infracciones que pueden ser sancionadas con cualquiera de las medidas que en dicho precepto se seńalan, pero no respecto de aquellas faltas administrativas que sólo pueden ser castigadas con una sanción específica fijada por la ley, como ocurre en la situación de la especie." ${ }^{30}$.

En suma, la jurisprudencia administrativa entiende, al menos en este caso, que toda infracción al artículo 62 de la ley $\mathrm{N}^{\circ} 18.575$ debe necesariamente ser castigada con la medida de destitución que contempla el artículo 125 del Estatuto.

\section{Los casos recientes}

En el último tiempo ha habido diversos pronunciamientos que han vinculado la probidad administrativa con la apoliticidad de los funcionarios que desempeñan cargos directivos en la Administración del Estado. Se trata de dictámenes que afectan el concepto mismo de función pública y de los deberes de los ministros de Estado.

\section{Caso 1: Los ministros de Estado y su responsabilidad administrativa}

El primer caso dice relación con la responsabilidad administrativa de los ministros de Estado. Históricamente la Contraloría General sostuvo que los Ministros de Estado no eran funcionarios públicos y que en caso que ellos incurrieran en una infracción administrativa, ella debía colocar los antecedentes a disposición de la Cámara de Diputados para que esta decidiese si iniciaba una acusación constitucional en su contra.

30 Dictamen $\mathrm{N}^{\circ} 49.465 / 06$. 
En este sentido, sostuvo que los Secretarios de Estado, por su rol de colaboradores directos del Presidente de la República no son funcionarios públicos y no están subordinados a las disposiciones sobre responsabilidad administrativa contenidas en la ley $\mathrm{N}^{\circ} 18.834^{31}$, que por la misma razón si bien están sujetos a responsabilidad civil, penal y política, "no procede la instrucción de sumarios administrativos en su contra"32, o que no se encuentran sometidos a las normas sobre responsabilidad administrativa, sino a aquellas disposiciones que regulan su responsabilidad política ante el Congreso Nacional, sin perjuicio de la responsabilidad civil y penal que les pueda asistir ${ }^{33}$.

Este criterio encontraba su fundamento en el inciso segundo de la letra b) del artículo $2^{\circ}$ del decreto con fuerza de ley $\mathrm{N}^{\circ} 338$, que comentamos con anterioridad, conforme al cual los ministros de Estado no quedaban comprendidos en la denominación de 'empleado público' que ese literal definía, y que, por lo mismo, no les eran aplicables las disposiciones de ese texto legal, 'salvo aquellos preceptos en los cuales se les ha incluido expresamente. No obstante, el nuevo Estatuto Administrativo no contiene una exclusión como esa a favor de los secretarios de Estado y la jurisprudencia posterior a su dictación no pareció haber advertido ese detalle. Así, al menos a nivel doctrinal, el privilegio solo se sustentaba en el carácter de colaboradores directos e inmediatos que la Constitución Política y la ley $\mathrm{N}^{\circ} 18.575$ le conferían a esas autoridades.

No obstante, a partir del año 2009 mediante su dictamen N 48.097 la Contraloría General advierte esta debilidad argumentativa y modifica su jurisprudencia, sosteniendo a partir de entonces:

- Un cambio en el rol procedimental que correspondía adoptar frente a requerimientos que cuestionaran la actividad de los secretarios de Estado. No solo es procedente una acusación constitucional, sino que ella también puede y debe pronunciarse frente a eventuales infracciones que los ministros de Estado, en el ejercicio de sus funciones, pudiesen cometer contra las normas sobre probidad administrativa

- Por lo mismo, ella puede ordenar la apertura de un procedimiento sumarial, en cuanto "medio formal de establecer hechos sujetos a una investigación" y si el resultado de la indagación arroja antecedentes precisos y relevantes que permitan suponer la participación concreta de un ministro de Estado, e independientemente de las posibles sanciones aplicables en lo inmediato a otros funcionarios comprometidos, cabría remitir los antecedentes a la Cámara de Diputados para que ésta proceda como estime pertinente.

- Que los ministros de Estado, en tanto ciudadanos, conservan el derecho cívico a tener opiniones políticas y manifestar sus convicciones personales, lo que en

Dictamen $\mathrm{N}^{\circ} 44.672 / 99$.

Dictamen $\mathrm{N}^{\circ}$ 48.732/01, que aplicó los dictámenes $\mathrm{N}^{\circ}$ s. 17.735/75, 19.089/96, y 44.672/99.

Dictamen $\mathrm{N}^{\circ} 52.520 / 09$, que aplicó los dictámenes $\mathrm{N}^{\circ}$ s. 61.020/73, 19.089/96, 48.732/01, 40.458/03, y $19.888 / 05$. 
todo caso no debe hacerse durante su jornada de trabajo y sin emplear recursos públicos.

A partir del año 2012 comienza a formularse una doctrina más intensa sobre la probidad administrativa de los secretarios de Estado, y sostiene $e^{34}$ (1) que los ministros de Estado, en tanto ciudadanos, conservan el derecho cívico a tener opiniones políticas y manifestar sus convicciones personales, lo que en todo caso no debe hacerse durante su jornada de trabajo y sin emplear recursos públicos; (2) que los principios de legalidad, probidad administrativa y apoliticidad de la Administración del Estado constituye una obligación permanente de quienes desarrollan una función o cargo público, cuyo cumplimiento se extiende a todo el período en que se encuentren ejerciendo sus labores y no sólo a aquel en que se desarrolla un proceso electoral, y (3) que los ministros de Estado son colaboradores directos e inmediatos del Presidente de la República en las funciones de gobierno y administración de sus respectivos sectores. Así, sostuvo que cada ministerio tiene prescrito un campo de actuación previsto en la ley. En tal sentido concluyó que "las conductas que las autoridades ejecuten, o las actividades que ellos realicen, no pueden justificarse en pareceres vinculados a opiniones relativas al funcionamiento del sistema político nacional, o del bienestar común o de la posición general y abstracta propias de una opinión política, sino que han de relacionarse directamente con las competencias de las cuales dichas autoridades han sido dotadas por la Constitución y las leyes.

\section{Caso 2: Los conflictos de intereses}

En otra ocasión ${ }^{35}$, un grupo de parlamentarios sostuvieron que existiría un conflicto de interés entre el interés privado del Presidente de la República en su calidad de accionista de las empresas controladoras de la Red de Televisión Chilevisión S.A. y los nombramientos de las autoridades del Consejo Nacional de Televisión y de Televisión Nacional de Chile que le compete efectuar

En tal caso, la Contraloría General sostuvo al menos tres ideas centrales. El primer lugar, reiteró que el Presidente de la República se encuentra sometido, como todas las autoridades públicas, al principio de probidad. No obstante, añadió que esa autoridad, como todo ciudadano, puede desarrollar actividades económicas y está amparado por el derecho de propiedad, derechos que en todo caso pueden ser limitados por la ley.

En segundo término precisó que una posibilidad de establecer restricciones o limitaciones a las garantías aludidas, es la prevista en el citado artículo $8^{\circ}$, inciso cuarto, de la Constitución Política, el cual encomienda a una ley orgánica constitucional determinar los casos y las condiciones en que las autoridades a que se refiere delegarán a terceros la administración de aquellos bienes y obligaciones que supongan conflicto de interés en el ejercicio de su función pública; la que también podrá considerar otras 
medidas apropiadas para resolverlos. Asimismo, indicó que la ley puede, en situaciones calificadas, disponer la enajenación de todo o parte de esos bienes. Por último, atendido que esa ley orgánica constitucional no había sido dictada, no le correspondía a ella (a la Contraloría General) suplir la omisión legislativa ${ }^{36}$ y, por lo mismo, establecer mediante la vía dictaminadora restricciones al derecho de propiedad.

\section{Caso 3: El deber de abstención}

En un tercer caso, la Contraloría General debió analizar si el Ministro de Minería cumplió con el principio de probidad ya que, por razones de parentesco, debió abstenerse de participar en todas las actuaciones llevadas a cabo por la Secretaría de Estado que representa para la celebración de un contrato especial de operación sobre el litio. Tal caso era importante, no solo por la sensibilidad política que se generó a propósito de la licitación para el contrato especial de operación del litio. La Contraloría General recordó tres reglas:

- Reiteró, una vez más, que los ministros están sujetos al principio de probidad administrativa.

- Que el Nº 6 del artículo 62 de la Ley de Bases dispone que contraviene especialmente el principio de probidad administrativa, entre otras conductas, la de intervenir, en razón de las funciones, en asuntos en que se tenga interés personal o en que lo posean el cónyuge y los parientes que señala, como también participar en decisiones en que exista cualquier circunstancia que le reste imparcialidad, casos en los cuales las personas y funcionarios involucrados deberán abstenerse de intervenir, informando a su superior jerárquico la implicancia que les afecta.

- Que el mismo deber de abstención está previsto en el artículo 12 de la ley $\mathrm{N}^{\circ}$ 19.880, sobre Bases de los Procedimientos Administrativos que Rigen los Actos de los Órganos de la Administración del Estado, el cual contempla aquellas causales que en dichos procesos suponen ausencia de imparcialidad, imponiendo análoga obligación a los funcionarios en quienes concurran.

- Concluyó que de los antecedentes examinados permitían formarse la convicción que el Ministro de Minería comunicó al Presidente de la República que, atendido el lazo de parentesco que consigna y en cumplimiento al deber de abstención, no ha intervenido y se inhabilitará de participar en el proceso de formulación de

36 "Como puede apreciarse, el constituyente ha radicado exclusivamente en el Poder Legislativo, mediante el ejercicio de sus potestades privativas, la facultad de determinar aquellos bienes de propiedad de las autoridades que señala, y que las mismas deberán enajenar o entregar en administración a terceros por suponer un conflicto de interés.

Como lógica consecuencia, esta Entidad de Control carece de atribuciones para efectuar tal calificación o para disponer medidas de esa naturaleza, toda vez que la potestad dictaminante, y por ende interpretativa de las leyes que rigen a la Administración del Estado y que compete a este Organismo de Control, no es el adecuado sustituto al ejercicio cabal, oportuno e íntegro de un deber que corresponde exclusivamente al órgano legislativo.". 
políticas, evaluaciones y toma de decisiones asociadas al otorgamiento de derechos de explotación del litio.

- Que el decreto $\mathrm{N}^{\circ}$ 16, de 2012, del Ministerio de Minería, estableció los requisitos y condiciones del contrato especial de operación para la exploración, explotación y beneficio de yacimientos de litio, que el Estado de Chile suscribirá conforme a las bases de licitación pública nacional e internacional aprobadas para estos efectos. Dicho acto administrativo fue suscrito por el Ministro de Minería subrogante "Por orden del Presidente de la República" ${ }^{37}$,

De ello concluyó que el Ministro de Minería no participó en la dictación del aludido decreto $N^{\circ} 16$, de 2012, por lo que esta Entidad de Control no ha constatado infracciones al deber de abstención por el cual se consulta.

\section{Conclusión}

El principio de probidad administrativa ha ido teniendo un reconocimiento paulatino por la legislación nacional. En sus orígenes se vinculaba al concepto de deberes morales de los servidores públicos, lo cual era una clara confusión entre los sistemas normativos jurídico y moral, y la jurisprudencia de la Contraloría General de la República asimiló ambos conceptos. Posteriormente pasó a ser reconocido como tal por el Estatuto Administrativo y luego por la Constitución Política. Finalmente, la Contraloría General ha debido pronunciarse sobre la aplicación de las normas jurídicas constitucionales, legales y reglamentarias que regulan esta materia, en especial en lo relacionado con los conflictos de intereses y el deber de abstención de los ministros de Estado y del Presidente de la República, casos en los cuales ha sostenido que esas autoridades se encuentran sujetas a la regulación sobre la ética pública.

\section{Normas citadas}

Código Orgánico de Tribunales.

Decreto con fuerza de ley $\mathrm{N}^{\circ} 338$, de 1960, del Ministerio de Hacienda.

Decreto $N^{\circ}$ 19, de 2001, del Ministerio Secretaría General de la Presidencia.

Ley $\mathrm{N}^{\circ} 20.088$, establece como obligatoria la declaración jurada patrimonial de bienes a las autoridades que ejercen una función pública.

Ley No 18.695, Orgánica Constitucional de Municipalidades.

Ley No 18.834, sobre Estatuto Administrativo.

37 Conforme al decreto $N^{\circ} 19$, de 2001, del Ministerio Secretaría General de la Presidencia, que faculta a los ministros de Estado para firmar decretos supremos relativos a las materias que indica. 
Ley No 18.883, sobre Estatuto Administrativo de los Funcionarios Municipales.

Ley No 18.918, Orgánica Constitucional del Congreso nacional.

Ley No 19.175, Orgánica Constitucional de Gobierno y Administración Regional. Ley No15.231, sobre organización y atribuciones de los Juzgados de Policía Local Ley No18.046, sobre Sociedades Anónimas.

Ley No18.840, Orgánica Constitucional del Banco Central de Chile.

\section{JURISPRUDENCIA CITADA}

Dictamen $\mathrm{N}^{\circ} 38.165 / 60$

Dictamen $\mathrm{N}^{\circ} 75.758 / 60$

Dictamen $\mathrm{N}^{\circ}$ 68.648/62

Dictamen $\mathrm{N}^{\circ} 35.897 / 62$

Dictamen $\mathrm{N}^{\circ}$ 15.958/62

Dictamen $N^{\circ}$ 64.298/60

Dictamen $\mathrm{N}^{\circ}$ 64.792/67

Dictamen $\mathrm{N}^{\circ} 7.521 / 68$

Dictamen $\mathrm{N}^{\circ} 13.122 / 86$

Dictamen $\mathrm{N}^{\circ} 38.691 / 88$

Dictamen $N^{\circ} 40.623 / 88$

Dictamen $\mathrm{N}^{\circ} 44.672 / 99$

Dictamen $\mathrm{N}^{\circ}$ 65.176/00

Dictamen $\mathrm{N}^{\circ} 30.733 / 00$

Dictamen $N^{\circ}$. 6.591/00

Dictamen $\mathrm{N}^{\circ} 39.497 / 00$

Dictamen $\mathrm{N}^{\circ}$ 19.383/01

Dictamen $N^{\circ} 31.116 / 01$

Dictamen $\mathrm{N}^{\circ}$ 48.732/01

Dictamen $N^{\circ}$ 18.721/02

Dictamen $N^{\circ} 39.410 / 03$

Dictamen $\mathrm{N}^{\circ} 40.152 / 04$ 
Dictamen $\mathrm{N}^{\circ} 140 / 04$

Dictamen $N^{\circ} 58.851 / 04$

Dictamen $N^{\circ} 16.115 / 04$

Dictamen $N^{\circ} 49.465 / 06$

Dictamen $N^{\circ} 26.949 / 07$

Dictamen N ${ }^{\circ} 44.405 / 07$

Dictamen N ${ }^{\circ} 47.184 / 07$

Dictamen $N^{\circ} 5.670 / 07$

Dictamen $N^{\circ} 25.332 / 08$

Dictamen N ${ }^{\circ} 49.580 / 08$

Dictamen $N^{\circ} 61.379 / 08$

Dictamen N62.498/08

Dictamen $N^{\circ} 52.520 / 09$

Dictamen $N^{\circ} 7.727 / 10$

Dictamen $N^{\circ} 34.834 / 10$

Dictamen $N^{\circ} 39.453 / 10$

Dictamen N ${ }^{\circ} 42.592 / 11$

Dictamen $\mathrm{N}^{\circ} 15.401 / 11$

Dictamen $N^{\circ} 49.659 / 11$

Dictamen $N^{\circ} 61.301 / 12$

Tribunal Constitucional sentencia, 19 de Noviembre de 1999, Rol N²99. 